\title{
Article \\ Differential DNA Methylation in Prostate Tumors from Puerto Rican Men
}

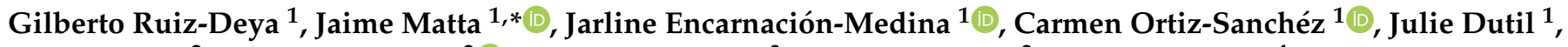 \\ Ryan Putney ${ }^{2}$, Anders Berglund ${ }^{2} \mathbb{D}$, Jasreman Dhillon ${ }^{3}$, Youngchul Kim ${ }^{2}$ and Jong Y. Park ${ }^{4}$
}

1 Department of Basic Sciences, Ponce Research Institute, Ponce Health Sciences University-School of Medicine, Ponce 00716-2347, Puerto Rico; gruiz@psm.edu (G.R.-D.); jencarnacion@psm.edu (J.E.-M.); carmenortiz@psm.edu (C.O.-S.); jdutil@psm.edu (J.D.)

2 Department of Biostatistics and Bioinformatics, H. Lee Moffitt Cancer Center, Tampa, FL 33612, USA; ryan.putney@moffitt.org (R.P.); anders.berglund@moffitt.org (A.B.); youngchul.kim@moffitt.org (Y.K.)

3 Department of Pathology, H. Lee Moffitt Cancer Center, Tampa, FL 33612, USA; Jasreman.Dhillon@moffitt.org

4 Department of Cancer Epidemiology, H. Lee Moffitt Cancer Center, Tampa, FL 33612, USA; jong.park@moffitt.org

* Correspondence: jmatta@psm.edu; Tel.: +1-787-259-7025

check for updates

Citation: Ruiz-Deya, G.; Matta, J.; Encarnación-Medina, J.;

Ortiz-Sanchéz, C.; Dutil, J.; Putney, R.; Berglund, A.; Dhillon, J.; Kim, Y.; Park, J.Y. Differential DNA Methylation in Prostate Tumors from Puerto Rican Men. Int. J. Mol. Sci. 2021, 22, 733. https://doi.org/ 10.3390/ijms22020733

Received: 23 November 2020 Accepted: 29 December 2020 Published: 13 January 2021

Publisher's Note: MDPI stays neutral with regard to jurisdictional clai$\mathrm{ms}$ in published maps and institutional affiliations.

Copyright: (C) 2021 by the authors. Licensee MDPI, Basel, Switzerland. This article is an open access article distributed under the terms and conditions of the Creative Commons Attribution (CC BY) license (https:// creativecommons.org/licenses/by/ $4.0 /)$.

\begin{abstract}
In 2020, approximately 191,930 new prostate cancer (PCa) cases are estimated in the United States (US). Hispanic/Latinos (H/L) are the second largest racial/ethnic group in the US. This study aims to assess methylation patterns between aggressive and indolent PCa including DNA repair genes along with ancestry proportions. Prostate tumors classified as aggressive $(n=11)$ and indolent $(n=13)$ on the basis of the Gleason score were collected. Tumor and adjacent normal tissue were annotated on H\&E (Haemotoxylin and Eosin) slides and extracted by macro-dissection. Methylation patterns were assessed using the Illumina 850K DNA methylation platform. Raw data were processed using the Bioconductor package. Global ancestry proportions were estimated using ADMIXTURE $(\mathrm{k}=3)$. One hundred eight genes including AOX1 were differentially methylated in tumor samples. Regarding the PCa aggressiveness, six hypermethylated genes (RREB1, FAM71F2, JMJD1C, COL5A3, RAE1, and GABRQ) and 11 hypomethylated genes (COL9A2, FAM179A, SLC17A2, PDE10A, PLEKHS1, TNNI2, OR51A4, RNF169, SPNS2, ADAMTSL5, and CYP4F12) were identified. Two significant differentially methylated DNA repair genes, JMJD1C and RNF169, were found. Ancestry proportion results for African, European, and Indigenous American were 24.1\%, 64.2\%, and $11.7 \%$, respectively. The identification of DNA methylation patterns related to PCa in $\mathrm{H} / \mathrm{L}$ men along with specific patterns related to aggressiveness and DNA repair constitutes a pivotal effort for the understanding of PCa in this population.
\end{abstract}

Keywords: prostate cancer; DNA methylation; aggressive prostate cancer; indolent prostate cancer; Gleason score; Hispanic/Latino; DNA repair; ancestry

\section{Introduction}

Since 1984, prostate cancer (PCa) has been the most commonly diagnosed cancer in the United States (US), currently accounting for 19\% of all cancers in men. Approximately $12.1 \%$ of men will be diagnosed with PCa in their lifetime [1]. In 2020, approximately 191,930 new PCa cases and 33,330 deaths are estimated in the US [2]. Hispanic/Latinos $(\mathrm{H} / \mathrm{L})$ are the second largest racial/ethnic group in the US after non-Hispanic Whites (NHWs). Chinea et al. (2017) reported that H/L subgroups have different prostate cancerspecific mortality (PCSM) rates when compared to NHWs and non-Hispanic Blacks (NHBs) using data from 2000-2013 that included 486,865 men. PCa incidence and mortality rates in H/L men were similar to NHWs [3]. However, these data may be overgeneralized because all $\mathrm{H} / \mathrm{L}$ subgroups are aggregated into one broad group. Data from the Puerto Rico (PR) Cancer Registry show that PCa is the leading cancer type, both in terms of incidence (39.9\% 
of all cancer cases) and in terms of mortality ( $18.3 \%$ of all cancer deaths) [4]. A recent study reported that Puerto Rican H/L (PR H/L) men have a higher rate of survival and treatment outcomes than NHWs [3]. However, PR H/L men had significantly higher PCSM than NHBs and the highest mortality among Hispanic subgroups [3].

PCa diagnosis is mainly based on the evaluation of biopsied tissue by a pathologist that produces a Gleason score of disease severity. This is associated with an average error of $25-30 \%$ in the case of under-detection and an average error of $1.3-7.1 \%$ in the case of over-detection $[5,6]$. The accuracy of a Gleason score is estimated to be $61 \%[7,8]$. Although PCa is normally characterized by a slow progression, about $20-30 \%$ of cases are associated with an aggressive phenotype that could lead to metastasis and death. A key molecular feature of this aggressive phenotype is the dysregulation of tumor suppressor genes and DNA repair genes. Defects in DNA repair pathways in PCa can be effectively targeted using PARP1 inhibitors. Prostate tumors with deficiencies in BRCA1 or BRCA2 DNA repair genes are highly sensitive to these drugs [9]. Although alterations of these genes in prostate tumors have been studied [10,11], little is known about the epigenetic regulation of DNA repair genes in PCa. No published data are currently available regarding DNA methylation in PR H/L PCa patients.

Epigenetic changes and modifications represent critical components of initiation and progression of carcinogenesis [12]. Abnormal epigenetic programs, including DNA methylation may inactivate large groups of genes. Hundreds of epigenetically silenced genes may exist in tumor tissues [13]. DNA methylation has been extensively studied, and hypermethylation has been linked with gene silencing of tumor suppressor genes in $\mathrm{PCa}$ and with adverse clinical outcomes [12,14-16]. DNA methylation is an epigenetic process that affects transcriptional regulation of genes. DNA methylation occurs when a methyl branch is added to position 5 of cytosine, and normally $3-4 \%$ of all cytosines are methylated [13]. Methylation only occurs at cytosine nucleotides located $5^{\prime}$ to guanine nucleotides forming CpGs or their clusters, termed CpG islands. DNA methylation is part of a cluster of molecular processes that initiate tumorigenesis and drive its early evolution by altering other molecular processes.

We previously reported that numerous studies have investigated DNA methylation in PCa $[17,18]$. These studies reported a number of differentially methylated genes in PCa compared to adjacent normal tissues. Most of these studies used a candidate gene approach advantage to increase statistical efficiency of the study association analysis while narrowing the possibilities of assessing methylation effects related to multiple genes. Several studies used an epigenome-wide methylation microarray to cover a wide range of genes. All studies identified a large number of differentially methylated CpGs, but these findings have not been confirmed in independent validation datasets [19-21]. Since DNA methylation changes may drive racial and ethnic disparities in PCa [22], there is a need to study these patterns from different small cohorts to identify potential candidates to further conduct representative validation studies.

This study aimed to investigate epigenetic differences in terms of DNA methylation between tumor and adjacent normal prostate tissues. Moreover, we aimed to assess differences in DNA methylation patterns in aggressive (high risk) and indolent (low risk) $\mathrm{PCa}$ in order to identify specific biomarkers for the aggressive phenotype in PR H/L men. A secondary aim was to characterize the ancestry component of men in this study group. PR has an admixed population consisting of three main components: European, African, and Indigenous American.

\section{Results}

\subsection{Clinicopathological Characteristics of Study Group}

As shown in Table 1, PR H/L men in the aggressive (high-risk) group had a mean age of 65.5 and were significantly older than those in the indolent (low-risk) group, with a mean age of 59.4 years. As expected, because of the selection criteria used, the high-risk group showed significant differences in Gleason scores as compared with the low-risk 
group. No differences between the two groups were evident in terms of prostate-specific antigen (PSA) levels, ethnicity, vital characteristics, biochemical recurrence, tumor stage, surgical margins, and family history of prostate cancer $(p>0.05)$.

Table 1. Clinicopathological characteristics of Puerto Rican men with aggressive (high-risk) $(n=11)$ and indolent (low-risk) $(n=13)$ prostate cancer in the study group.

\begin{tabular}{|c|c|c|c|}
\hline Risk & $\begin{array}{l}\text { High } \\
n=11\end{array}$ & $\begin{array}{c}\text { Low } \\
n=13\end{array}$ & $p$-Value ${ }^{1}$ \\
\hline Age at diagnosis & $65.5 \pm 4.1$ & $59.4 \pm 10.5$ & 0.006 \\
\hline PSA & $8.3 \pm 6.59$ & $9.23 \pm 9.33$ & 0.350 \\
\hline Vital status & & & 0.500 \\
\hline Deceased & 1 & 0 & \\
\hline Alive & 10 & 11 & \\
\hline Missing & 0 & 2 & \\
\hline Gleason score & & & $<0.0001$ \\
\hline 6 & 0 & 8 & \\
\hline $7(3+4)$ & 0 & 5 & \\
\hline $7(4+3)$ & 7 & 0 & \\
\hline $8-9$ & 4 & 0 & \\
\hline Biochemical recurrence (BCR) & & & 0.160 \\
\hline Yes & 3 & 1 & \\
\hline No & 7 & 12 & \\
\hline Missing & 1 & 0 & \\
\hline Clinical Stage & & & 0.330 \\
\hline $\mathrm{T} 2 \mathrm{a}$ & 1 & 3 & \\
\hline $\mathrm{T} 2 \mathrm{c}$ & 6 & 9 & \\
\hline T3a & 1 & 0 & \\
\hline $\mathrm{T} 3 \mathrm{~b}$ & 3 & 1 & \\
\hline Surgical margins & & & 0.480 \\
\hline Yes & 1 & 0 & \\
\hline No & 8 & 11 & \\
\hline Missing & 2 & 2 & \\
\hline Family history of prostate cancer & & & 0.830 \\
\hline No & 3 & 5 & \\
\hline Yes & 3 & 3 & \\
\hline Missing & 5 & 5 & \\
\hline
\end{tabular}

\subsection{Differences in Methylation Levels between Tumors and Adjacent Normal Tissue}

An initial quality control of our samples considering the missing values, $\beta$-value distributions, and principal component analysis (PCA) indicated that three samples (two tumor and one normal) did not meet our quality control and were excluded from further analysis. The unsupervised PCA model of the remaining samples showed a clear distinction between tumor and normal tissues in the first principal component (PC1), explaining $36.7 \%$ of the variation (Figure 1A). This indicates that there are considerable methylation changes between normal and tumor tissue. To further explore the methylation differences between normal and tumor tissue, we performed a two-group comparison. The false discovery rate (FDR)-corrected $p$-values $(q<0.01)$ and the mean difference $(\Delta \beta$-value $>0.3)$ between the two groups are presented in a volcano plot (Figure 1B). This analysis resulted in 945 significant probes, with a majority of the probes showing hypermethylation in tumor samples (Figure 1B). To identify differently methylated genes, we further required two consecutive probes within a gene to be significant and this resulted in 108 differently methylated genes (Supplementary Materials, Table S1). One of identified genes, AOX1, which was previously suggested as a methylation biomarker for PCa [21,23], showed significant hypermethylation for multiple probes in tumor tissue (Figure 1C). Using data from The Cancer Genome Atlas (TCGA), we show that this aberrant promoter methylation led to downregulation of $A O X 1$ in tumor tissues (Figure 1D). 
A

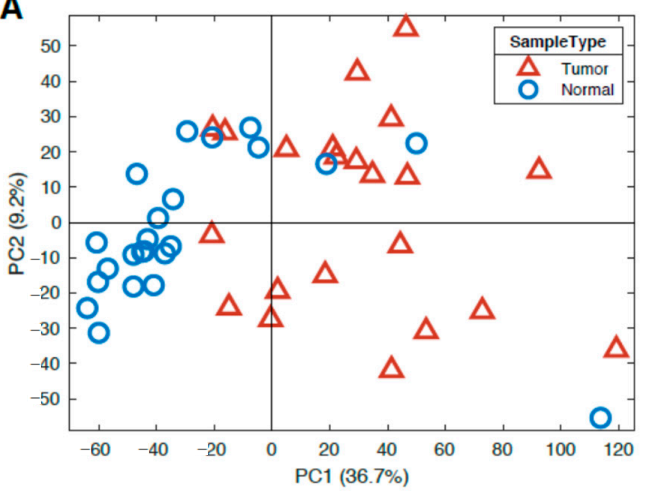

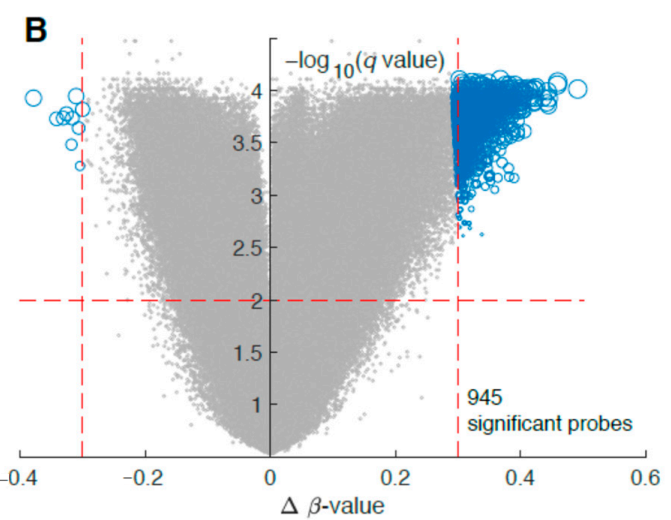

E

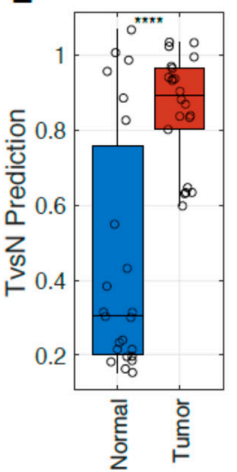

C

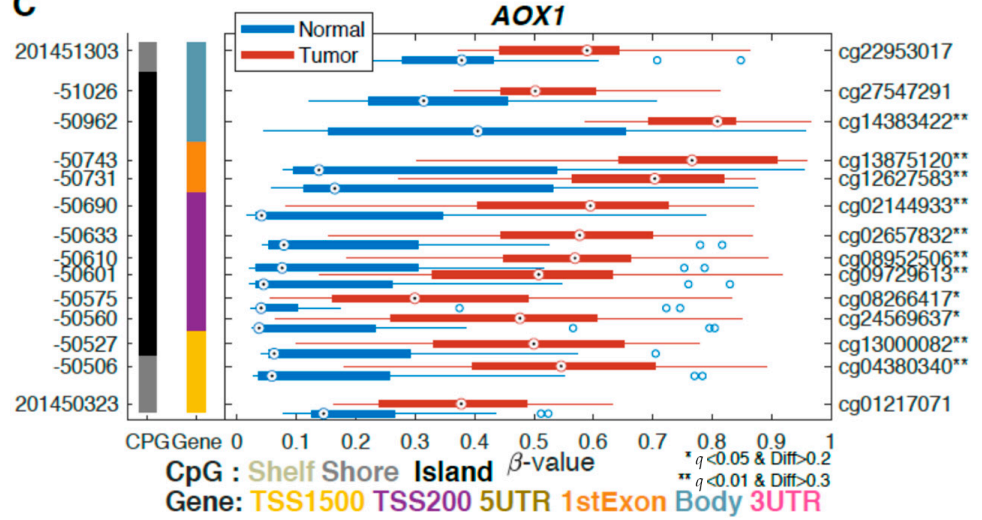

D

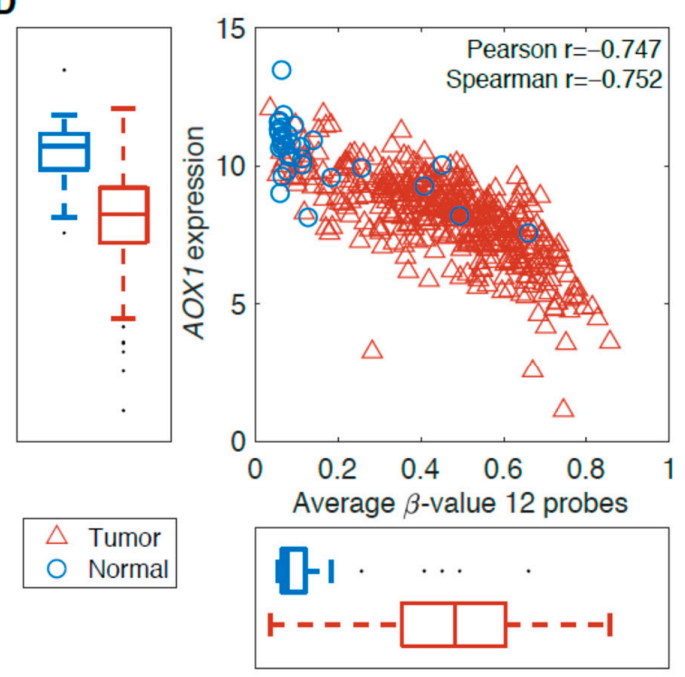

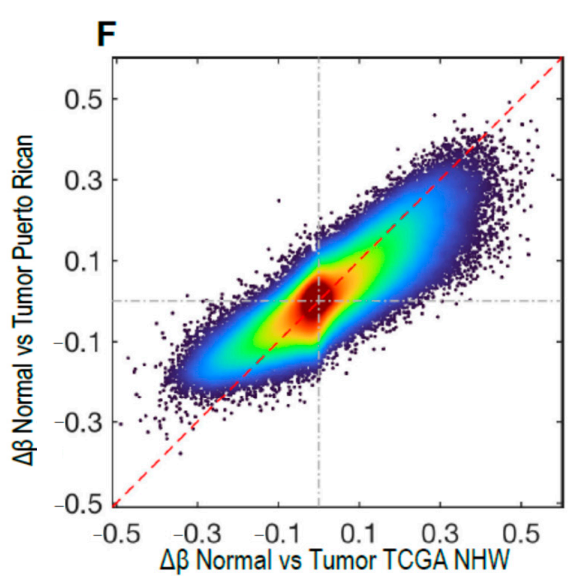

Figure 1. Methylation differences in tumors vs. normal tissue. (A) Principal component analysis (PCA) of 45 samples in our study shows a separation between tumor (red triangles, $n=22$ ) and adjacent normal tissue (blue circles, $n=23$ ). (B) The volcano plot above indicates changes in the methylation pattern between normal and tumor tissues with hypermethylated regions in tumors. (C) Gene structure methylation (GSM) plot for a representative gene, AOX1. The methylation level ( $x$-axis) for each probe set is represented by a boxplot for each group with tumors in red and normal in blue. The genomic and the probe identifier (ID) are shown on the left and right $y$-axis, respectively. The far-left column (black) indicates the presence of a CpG island and the next column (colored) shows the CpG probe location in the gene. Multiple probes showed significant differential methylation level. (D) Average methylation level for 12 probes vs. RNA-seq gene expression levels show a negative correlation using The Cancer Genome Atlas Prostate Adenocarcinoma (TCGA-PRAD) non-Hispanic white (NHW) samples. (E) Partial least squares (PLS) model derived using TCGA NHW samples can clearly separate the samples from the Puerto Rico (PR) cohort. (F) Density scatter plot of $\Delta \beta$-values for overlapping probes for the TCGA Illumina $450 \mathrm{~K}$ probes vs. PR cohort (EPIC) probes. ${ }^{* * *} p<0.0001$. 
To further investigate our data, we integrated the methylation results on a partial least squares (PLS) model for tumor vs. normal using only non-Hispanic White (NHW) samples from The Cancer Genome Atlas Prostate Adenocarcinoma (TCGA-PRAD) dataset. Applying this PLS model to our data, we can observe that samples of Puerto Rican origin show similar methylation changes when comparing tumor and normal tissues for the two datasets (Figure 1E). This is further established (Figure 1F) when comparing the $\Delta \beta$-value between tumors and normal for TCGA NHWs and this PR cohort, which shows a clear linear tendency. Of the 945 significant probes found in the PR cohort, 799 are available on the $450 \mathrm{~K}$ chip used by the TCGA and 585 (73\%) of these were also significant in the TCGA NHW cohort.

\subsection{Differentially Methylated Genes Associated with Aggressive Prostate Cancer}

To further investigate the differentially methylated genes in prostate tumor samples, we calculated a PCA model including 22 tumor samples identified as aggressive (high-risk) and indolent (low-risk). No clusters were found on the sample score plot between aggressive and indolent cases (Figure 2A). No significant results were obtained when comparing between the indolent and aggressive groups using FDR (0.84). However, 23 probes were identified as potential candidates using a $p<0.001$ and a $\Delta \beta$-value of 0.2 as cutoff (Figure 2B and Table 2).

Table 2. Differentially methylated genes between aggressive (high-risk) and indolent (low-risk) prostate tumors in Puerto Rican men with prostate cancer.

\begin{tabular}{|c|c|c|c|c|c|c|c|c|}
\hline Probe ID & Gene Symbol & GeneBody & Chr & Position & $p$-Value & $\begin{array}{c}\text { Delta } \\
\beta \text {-Value }\end{array}$ & $\begin{array}{c}\text { Mean } \\
\text { (Low-Risk) }\end{array}$ & $\begin{array}{c}\text { Mean } \\
\text { (High-Risk) }\end{array}$ \\
\hline cg22030684 & COL9A2 & Body & 1 & $40,781,708$ & 0.000067 & -0.213457 & 0.449935 & 0.236478 \\
\hline cg25161377 & FAM179A & Body & 2 & $29,237,783$ & 0.000126 & -0.221753 & 0.654878 & 0.433124 \\
\hline cg15218485 & RREB1 & Body & 6 & $7,201,665$ & 0.000899 & 0.220195 & 0.238283 & 0.458478 \\
\hline cg24163360 & $S L C 17 A 2$ & TSS1500 & 6 & $25,931,557$ & 0.000087 & -0.218759 & 0.685592 & 0.466833 \\
\hline cg25641223 & PDE10A & Body & 6 & $165,747,945$ & 0.000104 & -0.200032 & 0.640184 & 0.440152 \\
\hline cg11747142 & $F A M 71 F 2$ & TSS200 & 7 & $128,312,331$ & 0.00054 & 0.229507 & 0.477201 & 0.706708 \\
\hline cg17983571 & JMJD1C & Body & 10 & $65,186,953$ & 0.000427 & 0.23785 & 0.470854 & 0.708704 \\
\hline cg05363118 & PLEKHS1 & $5^{\prime} \mathrm{UTR}$ & 10 & $115,523,310$ & 0.000081 & -0.206065 & 0.589143 & 0.383078 \\
\hline cg05258834 & TNNI2 & Body & 11 & $1,862,477$ & 0.000455 & -0.24573 & 0.648741 & 0.403012 \\
\hline cg21359838 & OR51A4 & TSS1500 & 11 & $4,969,708$ & 0.000186 & -0.212002 & 0.572201 & 0.360198 \\
\hline cg25921194 & RNF169 & Body & 11 & $74,492,567$ & 0.000161 & -0.24419 & 0.624767 & 0.380577 \\
\hline cg19092163 & SPNS2 & Body & 17 & $4,403,417$ & 0.00075 & -0.231457 & 0.433052 & 0.201596 \\
\hline cg15002904 & ADAMTSL5 & Body & 19 & $1,510,692$ & 0.000368 & -0.242087 & 0.496689 & 0.254602 \\
\hline cg17713488 & COL5A3 & Body & 19 & $10,077,935$ & 0.000157 & 0.360569 & 0.405099 & 0.765668 \\
\hline cg22669123 & CYP4F12 & TSS1500 & 19 & $15,782,644$ & 0.000677 & -0.215233 & 0.627928 & 0.412695 \\
\hline cg09154639 & RAE1 & TSS1500 & 20 & $55,925,570$ & 0.000905 & 0.226258 & 0.561288 & 0.787546 \\
\hline cg14539730 & $G A B R Q$ & Body & $x$ & $151,809,946$ & 0.000227 & 0.389047 & 0.362807 & 0.751854 \\
\hline
\end{tabular}


A

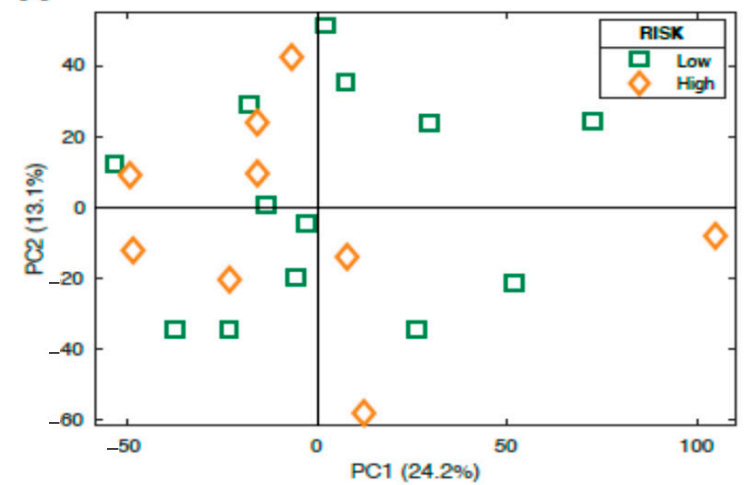

B

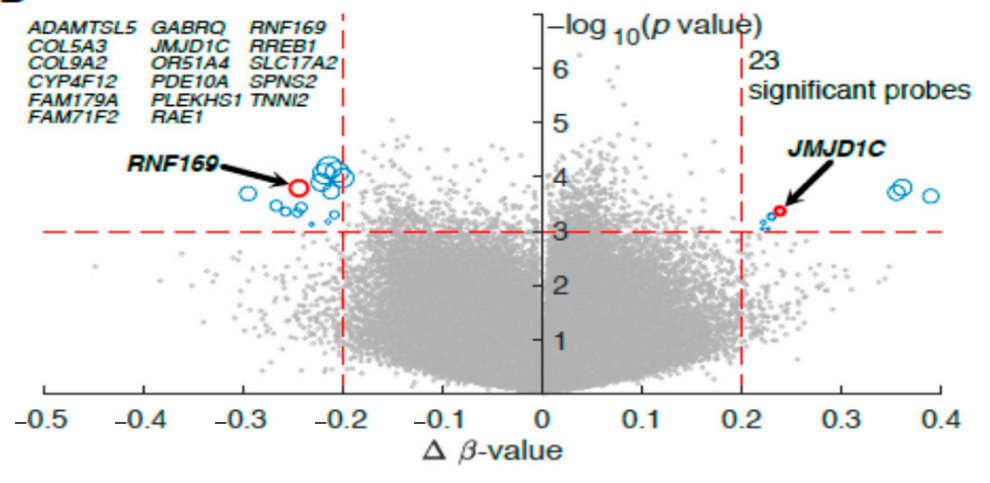

C

FAM71F2

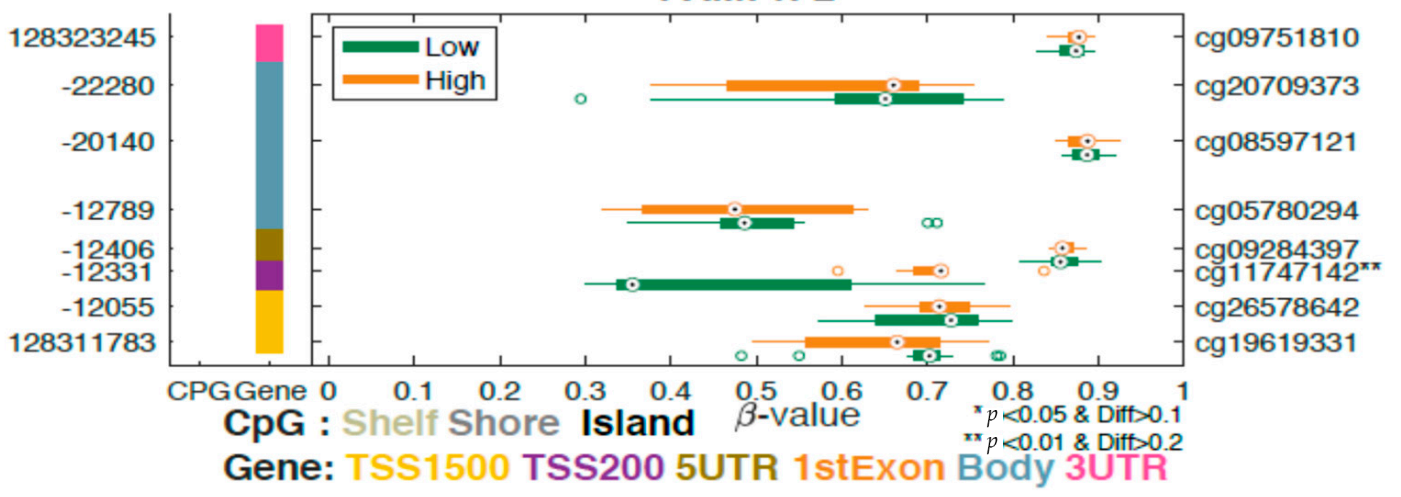

D

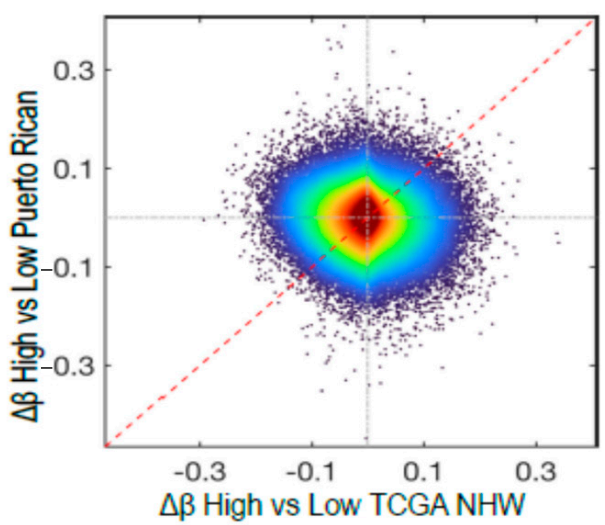

E

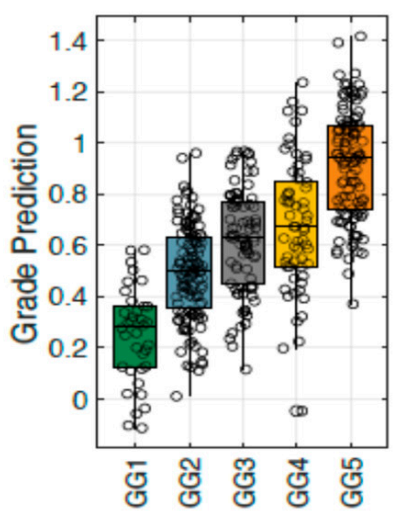

$\mathbf{F}$

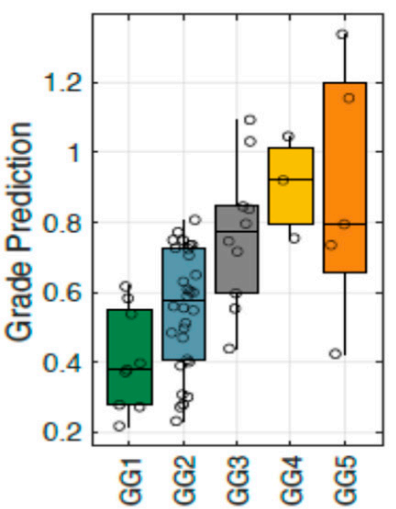

G

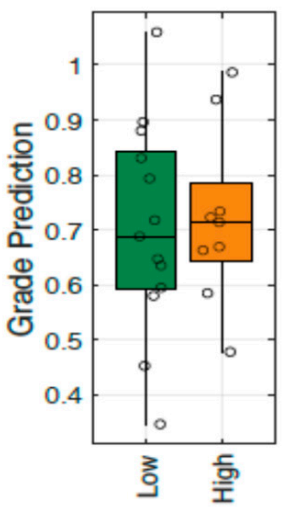

Figure 2. Methylation differences in high-grade vs. low-grade prostate tumors. (A) PCA of 22 samples in our study shows no separation between low-risk (green rectangles, $n=13$ ) and high-risk (orange diamonds, $n=9$ ) groups. (B) Volcano plots highlighting 23 differentially methylated sites between high-risk and low-risk prostate tumors with a $-\log _{10} p$-value on the $y$-axis and $\Delta \beta$-value on the $x$-axis. (C) GSM plot for FAM71F2 demonstrating lower level of methylation for the low-risk group compared to the high-risk group for cg11747142. (D) Density scatter plot comparing the $\Delta \beta$-value for GG1 vs. GG5 for the TCGA PRAD NHW samples compared to the $\Delta \beta$-value for the high-risk vs. low risk Puerto Rican samples. Prediction results for a PLS model derived using (E) TCGA PRAD NHW GG1 vs. GG5 applied to the TCGA NHW samples, (F) TCGA non-Hispanic Black (NHB) samples, and (G) Puerto Rican samples. 


\subsection{Methylation Analysis of DNA Repair Genes Associated with Aggressive Prostate Cancer}

The volcano plot shows the significant differentially methylated $\mathrm{CpG}$ sites between aggressive and indolent prostate tumors found in 17 genes (Figure 2B). Six of these genes were hypermethylated (RREB1, FAM71F2, JMJD1C, COL5A3, RAE1, and GABRQ), and 11 were hypomethylated (COL9A2, FAM179A, SLC17A2, PDE10A, PLEKHS1, TNNI2, OR51A4, RNF169, SPNS2, ADAMTSL5, and CYP4F12). Table 2 presents the location of CpG sites, mean methylation levels in high- and low-risk groups and the $p$-values for these differentially methylated genes. One of the identified probes mapped to the gene named FAM71F2 (family with sequence similarity 71 member F2), which was previously suggested as a biomarker for metastasis of testicular cancer [24]. Probe cg11747142 was found to be significantly hypermethylated in tumor tissues (Figure 2C).

To compare our results with previous studies, we also included results from the NHW samples in the TCGA PRAD dataset (Figure 2E). The $\Delta \beta$-values for comparing Grade Group 1 (GG1) vs. Grade Group 5 (GG5) are compared to our $\Delta \beta$-value in Figure 2D. It is clear that there is no consistency in differently methylated probes between the two datasets, opposite to what was seen in Figure 1F. To further compare the two datasets, we derived a PLS model for the NHW samples using the GG1 vs. GG5. This model was applied to all the Grade Groups for the TCGA NHW samples (Figure 2E). For the sample used in the PLS model, GG1 and GG5 are clearly separated but there is also a clear trend difference among the GG2, GG3, and GG4 groups which were not part of the PLS model training set. To further validate our PLS model, we also applied it to the TCGA PRAD NHB samples (Figure 2F), and these predictions showed a similar trend as for the NHW samples. This would indicate that the NHW-derived PLS models also work on NHB samples. The PLS model was also applied to the PR cohort. However, it could not separate low-risk from high-risk samples (Figure 2G).

We analyzed differential methylation of 179 candidate DNA repair genes between tumor and normal tissues and between aggressive and indolent cases. These genes were predominantly distributed in five DNA repair pathways including nucleotide excision repair, base excision repair, mismatch repair, and homologous and nonhomologous repair. We found two significant differentially methylated DNA repair genes: JMJD1C and RNF169 (Figure 2B). JMJD1C (Figure 3A) codifies for a histone demethylase protein which plays a role in regulation of MDC1 protein expression [9]. RNF169 (Figure 3B) acts as a negative regulator of double-strand break (DSB) repair following DNA damage [25]. 

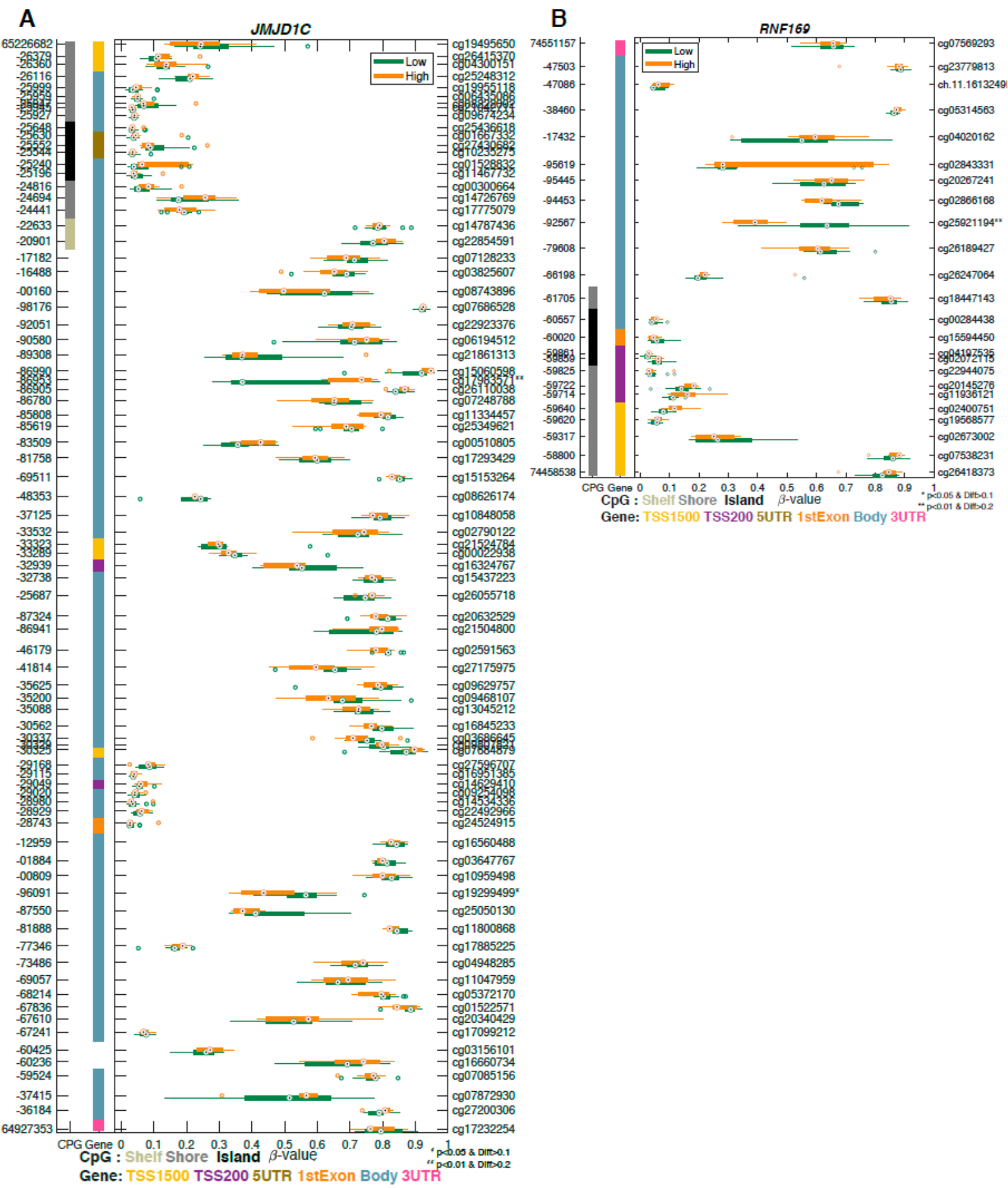

Figure 3. Two differentially methylated DNA repair genes associated with aggressiveness were found to contain probes with significant changes in methylation. GSM plots for (A) JMJDC1 and (B) RNF169 are shown.

\subsection{Ancestry Analysis}

For each study participant, we determined the proportion of African, European, and Indigenous American ancestry. As shown in Table 3, the contribution of African ancestry ranged between $2.7 \%$ and $85.8 \%$, averaging $24.1 \%$ (standard deviation, SD $22.6 \%$ ). For the European ancestry component, values ranged between $9.4 \%$ and $97.1 \%$, averaging $64.2 \%$ (SD 21.1\%). For the Indigenous American, values ranged between $0 \%$ and $25.16 \%$, averaging $11.7 \%$ (SD 9.0\%). It is noteworthy that, within this population, there are large 
variations in the contribution of European versus African ancestry, while the Indigenous American ancestry remains relatively homogenous (Table 3, Figure 4). This contrasts with what has been observed in H/L of Mexican and Peruvian origin for which there is a stronger influence of Indigenous American ancestry.

Table 3. Ancestry proportions in the study cohort of 23 Puerto Rican men with prostate cancer.

\begin{tabular}{ccccc}
\hline Ancestral Population & Average & SD & Maximum & Minimum \\
\hline African & 0.2408 & 0.2256 & 0.8576 & 0.0274 \\
European & 0.6420 & 0.2181 & 0.9716 & 0.0938 \\
Indigenous American & 0.1173 & 0.0897 & 0.2516 & 0 \\
\hline
\end{tabular}

SD: standard deviation.

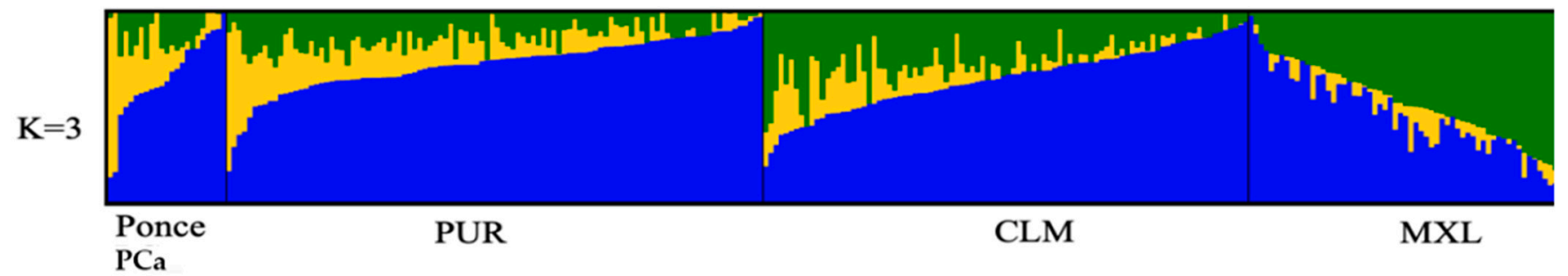

Figure 4. Visualization of the ancestry proportions for each individual in 23 PR H/L men with PCa (Ponce PCa) compared to 1000 Genomes Admixed Americans populations. Assuming three ancestral populations $(\mathrm{k}=3)$, each column represents one individual, and each color corresponds to the contribution of each ancestral population to the genome of a given individual (blue $=$ European, yellow $=$ African, and green = Indigenous American). PUR Puerto Ricans from Puerto Rico, MXL Mexican Ancestry from Los Angeles, CLM Colombians from Medellin, Colombia, and PEL Peruvians from Lima, Peru from the 1,000 Genomes project.

\section{Discussion}

This pilot study represents the first effort to study epigenetic regulation in PR H/L men with PCa. Several potential DNA methylation biomarkers for aggressive and indolent prostate tumors were identified. Our results integrate data from TCGA NHW and NHB which provides a perspective regarding methylation patterns in PR H/L men. Moreover, two differentially methylated protein-coding genes associated with DNA repair were identified, shedding light on the differences between aggressive and indolent PR H/L men with PCa. The outcomes of this study could lead to the development of better methods for clinicians to identify PR H/L men with PCa with low and high risk.

Our study is not the first to identify differences in methylation patterns between tumor and adjacent normal tissue in PCa. Using epigenome-wide 450K DNA methylation data derived from 469 PCa tumors and 50 normal prostatic tissue samples, Nikas and Nikas (2019) were able to develop a mathematical model that classified prostate tumor tissue versus normal tissue with a high sensitivity $(95.3 \%)$ and specificity $(94.0 \%)$ [8]. Since this group only compared tumor with adjacent normal tissues, their results cannot reflect differences within prostate tumors (aggressive and indolent). Our study is an effort to combine adjacent normal and tumor tissue to explore other differences that might be related to biological processes. Xu et al. (2019) investigated 553 PCa tumor samples in the TCGA database associated with DNA methylation-driven genes between tumor and normal samples. Here, we show that there are common methylation patterns between PR $\mathrm{H} / \mathrm{L}$ and NHWs [12].

One of identified genes, $A O X 1$, showed significant hypermethylation for multiple probes in tumor tissue. The most promising methylation marker candidates identified by Strand et al. (2014) included PITX2, C1orf114 (CCDC181), and the GABRE miR-452 miR224 locus, in addition to the three-gene signature AOX1/C1orf114/HAPLN3 [23]. The function of $F A M 71 F 2$ is unknown although this gene is expressed in various tissues including testis, brain, and others. Gene expression analysis in testis cancer identified family 
with sequence similarity 71, member F2 (FAM71F2), which can discriminate the metastasis status with an excellent predictive significance [24].

Among 17 differentially methylated genes in aggressive cases, a few genes, such as SLC17A2 and OR51A4, were not investigated previously for human cancers. However, most genes were investigated for a role in the methylation process, DNA repair, or differential expression in various tumors, including prostate cancer.

Differential expression of COL9A2 in prostate tumor was reported as compared in normal tissues. COL9A2 was found as one of the hub genes in a protein-protein interaction network [26]. The zinc finger protein Ras-responsive element binding protein (RREB-1) interacts with androgen receptor (AR) as a partner and coregulator. The RREB-1 gene binds to the prostate-specific antigen (PSA) promoter. Inhibition of $R R E B-1$ expression leads to increased PSA promoter activity and expression. Therefore, RREB-1 acts as a repressor of AR [27,28]. CYP4F12 is expressed differentially in colon [29] and liver tumor tissues [30,31]. Expression of CYP4F12 is positively correlated with low clinical stages and is a prognostic biomarker for overall survival in liver cancer. These results suggest the potential predictive diagnostic and prognostic roles of CYP4F12 gene expression in liver cancer [30].

Gene expression profiling analysis showed that $C O L 5 A 3$ overexpression is related to breast cancer progression [32]. ADAMTSL5 was proposed as a putative epigenetic marker for therapeutic resistance in acute lymphoblastic leukemia. Results from two methods, $27 \mathrm{~K}$ microarray and methylation-specific polymerase chain reaction, showed hypermethylation of ADAMTSL5 in chemo-resistant samples (93\% vs. 38\%; $p=0.0001$ ) [33]. RAE1 was identified as one of 23 genes involved in the transformation from androgen-dependent $\mathrm{PCa}$ to castrate-resistant PCa. These 23 genes play a role in important biological processes, such as cell signal transduction, cell adhesion, apoptosis, oncogenesis, cell proliferation, and cell differentiation [34].

Spinster homolog 2 (SPNS2) is a multi-transmembrane transporter, widely located in the cell membrane and organelle membranes. It transports sphingosine 1-phosphate (S1P) into the extracellular space and the circulatory system [35]. Sphingosine 1-phosphate (S1P) plays important roles in cell proliferation, differentiation, or survival mainly through its surface G-protein-coupled receptors S1P1-5. Bone represents the major site of metastasis for PCa cells, which rely on bone-derived factors to support their proliferation and resistance to therapeutics in PCa [36]. The SPIN2 gene is known to be involved in angiogenesis, immune response, and metabolism. Furthermore, Spindlin Family Member2 (SPIN2) is associated with the transformation from inflammation to cancer and metastasis. A critical role of SPIN2 was reported in the survival of lung cancer [37] and acute myeloid leukemia (AML) [38].

Troponin I2 (TNNI2) was identified as a candidate biomarker for prediction of poor outcomes in various cancers. Overexpression of TNNI2 is associated with recurrence and metastasis in gastric cancer [39] and with poor survival in lung cancer [40]. TNNI2 was hypomethylated in liver tumor [41]. Overexpression of Pleckstrin homology domain containing S1 (PLEKHS1) was associated with metastases, as well as shorter overall and disease-free survival in thyroid carcinoma. The messenger RNA (mRNA) expression of PLEKHS1 was inversely correlated with methylation level. PLEKHS1 plays a role in aggressive thyroid carcinoma and can be a biomarker for predicting poor outcomes [42].

The $F A M 179 A$ was identified as a fusion partner to the anaplastic lymphoma kinase gene (ALK) in patients with non-small-cell lung cancer (NSCLC). Therefore, this FAM179A$A L K$ fusion may influence the treatment response to ALK inhibitors [43]. $\gamma$-Aminobutyric acid (GABA) A receptor subunit $\theta(G A B R Q)$ is a well-known inhibitory neurotransmitter in the brain, suggested as a prognostic biomarker of clear cell renal cell carcinoma (ccRCC). Low $G A B R Q$ mRNA expression was significantly associated with a poor prognosis of ccRCC in two independent cohorts. GABRQ mRNA expression may be considered as a novel prognostic biomarker of ccRCC [44]. A previous study reported that GABRQ is involved in the risk and progression of liver cancer, which promotes the proliferation of cancer cells [45]. Phosphodiesterase10A (PDE10A) is expressed in prostate tissues. PDE10A 
was found frequently $(\approx 19 \%)$ in novel somatic mutations. In silico analysis of this novel variant shows a possible alteration of PCE10A function [46]. A biological role for PDE10A has also been studied in neurodegenerative diseases and in colorectal cancer $[47,48]$. Therefore, PDE10A-specific inhibitors are investigated in preclinical studies [49].

Among 17 genes associated with aggressiveness, two genes are involved in the DNA repair processes. JMJD1C, a DNA repair factor, plays multiple important roles in prostate cancer progression. Downregulation of JMJD1C leads to an impact on the DNA repair pathway in the balance of homologous recombination (HR) and non-homologous endjoining (NHEJ) [9]. JMJD1C shows focal loss in PCa and may be associated with resistance to PARP inhibitors [9]. In addition, a PCa genome-wide association study (GWAS) identified a new locus, JMJD1C at 10q21, which was associated with serum testosterone levels $\left(\right.$ rs10822184: $\left.p=1.12 \times 10^{-8}\right)$. This SNP in JMJD1C was estimated to account for $5.3 \%$ of the variance in serum testosterone and dihydrotestosterone levels. RNF169 is involved in the DNA repair pathway via an interaction with dual-specificity tyrosine phosphorylationregulated kinase 1A (DYRK1A), and it was reported to be involved in DNA double-strand break (DSB) repair [50,51]. RNF169 is recognized as a substrate for DYRK1A. RNF169 phosphorylation at $\mathrm{S} 688$ plays a major role in removing 53BP1 from the DNA damage foci [52]. Furthermore, RNF169 interacts with DYRK1A and localizes to DNA damage foci by binding [53].

Differentially methylated probes (585) were found when comparing tumor vs. normal tissue in PR H/L samples and further confirmed using the TCGA data. Kyoto Encyclopedia of Genes and Genomes (KEGG) pathway enrichment analysis based on DNA methylationdriven genes obtained from the Gene Expression Omnibus (GEO) database did not report any DNA repair pathways as being enriched in PCa. However, recent genomic analysis revealed that germline or somatic inactivation mutations in $B R C A 1$ or $B R C A 2$, or other genes involved in the homologous repair pathway collectively occur in as much as $20-25 \%$ of advanced PCa $[54,55]$. The identification of DNA methylation patterns related to PCa in PR H/L men along with specific patters related to aggressiveness and DNA repair constitutes a pivotal effort for the understanding of PCa disparities in this population. The study by Apprey et al. (2019) reported that genetic ancestry influences DNA methylation patterns [22]. This constitutes a unique effort to provide a broad overview regarding methylation and ancestry patterns in PR H/L men while opening new avenues for future studies.

\section{Materials and Methods}

\subsection{Human Subjects, Sample Selection, and Specimen Acquisition}

This study was approved by the Ponce Health Sciences University (PHSU) Institutional Review Board (Protocol no. 1909021277A001). All samples for this study were obtained from the Puerto Rico Biobank (PRBB), the only biorepository focused on the biobanking of Hispanic cancer patients from US. The PRBB is a core facility in Ponce Research Institute (PRI) and a key component of the U54 Partnership (PHSU/PRI-Moffitt Cancer Center) funded by the National Cancer Institute (NCI) Center to Reduce Cancer Health Disparities. Archived formalin-fixed paraffin-embedded (FFPE) blocks of 24 prostate tumor and 24 adjacent normal tissues were collected through the PRBB. We selected 11 aggressive and 13 indolent cases on the basis of Gleason scores.

\subsection{DNA Methylation}

\subsubsection{Illumina Methylation $850 \mathrm{~K}$ Data Filtering and Genome-Wide Analysis Plan}

The Illumina 850K DNA methylation platform (San Diego, CA) was used to measure DNA methylation patterns from FFPE isolated DNA according to the manufacturer's instructions. 


\subsubsection{DNA Extraction}

DNA samples were extracted from the FFPE prostate tissues from the PRBB core at PHSU using a macro-dissection approach. Tumor areas were annotated on the H\&E (Haemotoxylin and Eosin) slides by a pathologist (Dr. Jasreman Dhillon) and extracted by macro-dissection. To ensure the quality of the extracted nucleic acids, DNA extracted from the samples was evaluated for integrity with DNA integrity numbers (DINs).

\subsubsection{Quality Control (QC) and Normalization for Methylation Data}

The 'idat.files' were read using the minfi (version 1.28.4) [56,57] Bioconductor package for R (version 3.5.2). Detection $p$-values were subsequently calculated using minfi's implementation provided by the detectionP function. The function preprocessFunnorm was used to perform both background correction, using the normal-exponential out-of-band (NOOB) [58] method, and then functional normalization (FunNorm) [59], a between-array normalization method. The preprocessFunnorm function returned an object containing $\beta$-values which were calculated with an offset of 100 in the denominator, as suggested by Illumina [60]. The number of missing values, histogram of $\beta$-values, and principal component analysis (PCA) plots were used to visualize data quality and detect outlier samples and potential batch effects. $\beta$-Values with a corresponding detection $p$-value $>0.05$ were set as missing values.

\subsubsection{Selection of Differentially Methylated Regions (DMRs)}

Two group comparisons were performed using Student's $t$-test controlling for multiple testing using FDR [61]. Furthermore, probes were considered significant if the difference in mean $\beta$-value between the two groups was larger than 0.3 [62]. To further remove potentially false positives, we used a region-based analysis. This is accomplished by simultaneously considering all the probes within a specific region (gene or CpG island) and defining a significant change when multiple probes within that region show the same significant change [63-66]. A single significant probe within a CpG island or gene body was not considered significant. Statistical analysis was performed using MATLAB (Natick, MA, USA).

\subsubsection{TCGA Data}

Raw IDAT files were downloaded and normalized. RNA-seq data for PRAD was extracted from the PanCancer dataset (https: / /gdc.cancer.gov / about-data/publications / pancanatlas). Ancestry estimates were taken from the publication by Yuan et al. (2018) [67].

\subsection{Ancestry Analysis}

4.3.1. Genotyping

A set of 106 single-nucleotide polymorphisms (SNPs) that can discriminate indigenous American, African, and European ancestry was used to estimate the proportion of genetic ancestry in 24 PR H/L PCa patients. The ancestry informative markers (AIMS) are widely spaced throughout the genome and have a well-balanced distribution across all 22 autosomal chromosomes, with an average distance between markers of $2.4 \times 10^{7} \mathrm{bp}$. Genotyping of the ancestry informative markers was performed using a multiplex PCR coupled with single-base extension methodology with allele calls using a Sequenom analyzer at the University of Minnesota.

\subsubsection{Quality Control of Ancestry Data}

Out of the 106 AIMS genotyped, five were excluded due to a genotyping rate $<90 \%$ ( $n=2, \mathrm{rs} 30125, \mathrm{rs} 10491097)$ and / or weak confidence in clustering $(n=3, \mathrm{rs} 993314, \mathrm{rs} 2585901$, rs4076700). One individual with a call rate of $<90 \%$ was excluded from further analysis. 


\subsubsection{Ancestry Estimates}

The global genomic ancestry proportion was estimated using Admixture under a supervised model and assuming three populations of origin $(\mathrm{k}=3)$ using the -B (bootstrapping) flag to generate estimates of standard error. Reference populations for supervised analysis consisted of individuals of European ancestry $(n=42$, Coriell's North American Caucasian panel), African ancestry (37 non-admixed West Africans living in London, United Kingdom, and South Carolina), and Indigenous American (15 Mayans and 15 Nahuas).

Supplementary Materials: The following are available online at https://www.mdpi.com/1422-006 7/22/2/733/s1: Table S1. Differentially methylated CpG sites between tumor and adjacent normal prostate tissues

Author Contributions: Conceptualization, G.R.-D., J.M., J.E.-M., C.O.-S., and J.Y.P.; data curation, J.E.-M.; formal analysis, J.D. (Julie Dutil), R.P., A.B., and Y.K.; funding acquisition, G.R.-D., J.M., and J.Y.P.; investigation, G.R.-D., J.M., J.E.-M., C.O.-S., and J.Y.P.; methodology, J.E.-M., C.O.-S., R.P., A.B., J.D. (Jasreman Dhillon), and J.Y.P.; project administration, J.Y.P.; writing—original draft, G.R.-D., J.M., and J.Y.P.; writing—review and editing, G.R.-D., J.M., J.E.-M., J.D. (Julie Dutil), C.O.-S., R.P., A.B., J.D. (Jasreman Dhillon), Y.K. and J.Y.P. All authors have read and agreed to the published version of the manuscript.

Funding: This study and the Puerto Rico Biobank and Quantitative Sciences core were supported by the National Cancer Institute of the National Institutes of Health, NCI Center to Reduce Health Disparities with grants awarded to Ponce Health Sciences University (PHSU) and PHSU-Moffitt Cancer Center Partnership grants 5U54CA163071 and U54 CA163068.

Institutional Review Board Statement: The study was conducted according to the guidelines of the Declaration of Helsinki, and approved by the Institutional Review Board of Ponce Health Sciences University (Protocol code 1909021277A001, approved on 24 April 2019).

Informed Consent Statement: Informed consent was obtained from all subjects involved in the study.

Data Availability Statement: The data presented in this study are available on request from the corresponding author. The data are not publicly available due to privacy of participants.

Acknowledgments: The authors acknowledge the financial support from grants \# U54 CA163071 and U54 CA163068-07.

Conflicts of Interest: The authors declare no conflict of interest.

$\begin{array}{ll}\text { Abbreviations } \\ \text { PCa } & \text { Prostate cancer } \\ \text { DRC } & \text { DNA repair capacity } \\ \text { NER } & \text { Nucleotide excision repair } \\ \text { IRB } & \text { Institutional Review Board } \\ \text { DMR } & \text { Differentially methylated region } \\ \text { PR } & \text { Puerto Rico } \\ \text { H/L } & \text { Hispanic Latino } \\ \text { AA } & \text { African American } \\ \text { NHW } & \text { Non-Hispanic White } \\ \text { PCA } & \text { Principal component analysis } \\ \text { AIMS } & \text { Ancestry informative markers } \\ \text { QA } & \text { Quality assurance } \\ \text { QC } & \text { Quality control } \\ \text { FFPE } & \text { Formalin-fixed paraffin-embedded } \\ \text { SNPs } & \text { Single-nucleotide polymorphisms } \\ \text { TCGA } & \text { The Cancer Genome Atlas } \\ \text { FDR } & \text { False discovery rate }\end{array}$




\begin{tabular}{|c|c|}
\hline PCR & Polymerase chain reaction \\
\hline PHSU & Ponce Health Sciences University \\
\hline PRI & Ponce Research Institute \\
\hline PRBB & Puerto Rico Biobank \\
\hline HR & Homologous recombination \\
\hline PARP1 & Poly (ADP-Ribose) polymerase-1 \\
\hline BRCA1 & Breast cancer type 1 susceptibility protein \\
\hline BRCA2 & Breast cancer type 2 susceptibility protein \\
\hline DSBs & DNA double-strand breaks \\
\hline AOX1 & Aldehyde Oxidase 1 \\
\hline RREB1 & Ras Responsive Element Binding Protein 1 \\
\hline$F A M 71 F 2$ & Family with Sequence Similarity 71 F2 \\
\hline JMJD1C & Jumonji Domain Containing 1C \\
\hline COL5A3 & Collagen Type V Alpha 3 Chain \\
\hline RAE1 & Ribonucleic Acid Export 1 \\
\hline$G A B R Q$ & Gamma-Aminobutyric Acid Type A Receptor Subunit Theta \\
\hline COL9A2 & Collagen Type IX Alpha 2 Chain \\
\hline FAM179A & TOG Array Regulator of Axonemal Microtubules 2 \\
\hline SLC17A2 & Solute Carrier Family 17 Member 2 \\
\hline PDE10 & Phosphodiesterase 10 \\
\hline PLEKHS1 & Pleckstrin Homology Domain Containing S1 \\
\hline TNNI2 & Troponin I2, Fast Skeletal Type \\
\hline OR51A4 & Olfactory Receptor Family 51 Subfamily A Member 4 \\
\hline RNF169 & Ring Finger Protein 169 \\
\hline SPNS2 & Sphingolipid Transporter 2 \\
\hline ADAMTSL5 & ADAMTS Like 5 \\
\hline CYP4F12 & Cytochrome P450 Family 4 Subfamily F Member 12 \\
\hline MDC1 & Mediator of DNA Damage Checkpoint 1 \\
\hline PARP & Poly(ADP-Ribose) Polymerase \\
\hline$B R C A 1$ & BRCA1 DNA Repair Associated \\
\hline$B R C A 2$ & BRCA2 DNA Repair Associated \\
\hline
\end{tabular}

\section{References}

1. NCI. Cancer Stat Facts: Prostate Cancer; National Cancer Institute: Surveillance, Epidemiology, and End Results Program; Department of Health and Human Services: Bethesda, MD USA, 2018.

2. American Cancer Socitey. Cancer Facts \& Figures 2020; American Cancer Society: Atlanta, GA, USA, 2020.

3. Chinea, F.M.; Patel, V.N.; Kwon, D.; Lamichhane, N.; Lopez, C.; Punnen, S.; Kobetz, E.N.; Abramowitz, M.C.; Pollack, A. Ethnic heterogeneity and prostate cancer mortality in Hispanic/Latino men: A population-based study. Oncotarget 2017, 8, 69709-69721. [CrossRef] [PubMed]

4. Tortolero-Luna, G.; Zavala-Zegarra, D.; Pérez-Ríos, N.; Torres-Cintrón, C.R.; Ortíz-Ortíz, K.J.; Traverso-Ortíz, M.; Román-Ruiz, Y.; Veguilla-Rosario, I.; Vázquez-Cubano, N.; Merced-Vélez, M.F.; et al. Cancer in Puerto Rico, 2006-2010; Puerto Rico Central Cancer Registry: San Juan, PR, USA, 2013.

5. Ukimura, O.; Coleman, J.A.; de la Taille, A.; Emberton, M.; Epstein, J.I.; Freedland, S.J.; Giannarini, G.; Kibel, A.S.; Montironi, R.; Ploussard, G.; et al. Contemporary role of systematic prostate biopsies: Indications, techniques, and implications for patient care. Eur. Urol. 2013, 63, 214-230. [CrossRef] [PubMed]

6. Graif, T.; Loeb, S.; Roehl, K.A.; Gashti, S.N.; Griffin, C.; Yu, X.; Catalona, W.J. Under diagnosis and over diagnosis of prostate cancer. J. Urol. 2007, 178, 88-92. [CrossRef] [PubMed]

7. Goodman, M.; Ward, K.C.; Osunkoya, A.O.; Datta, M.W.; Luthringer, D.; Young, A.N.; Marks, K.; Cohen, V.; Kennedy, J.C.; Haber, M.J.; et al. Frequency and determinants of disagreement and error in gleason scores: A population-based study of prostate cancer. Prostate 2012, 72, 1389-1398. [CrossRef]

8. Nikas, J.B.; Nikas, E.G. Genome-Wide DNA Methylation Model for the Diagnosis of Prostate Cancer. ACS Omega 2019, 4, 14895-14901. [CrossRef]

9. Kurfurstova, D.; Bartkova, J.; Vrtel, R.; Mickova, A.; Burdova, A.; Majera, D.; Mistrik, M.; Kral, M.; Santer, F.R.; Bouchal, J.; et al. DNA damage signalling barrier, oxidative stress and treatment-relevant DNA repair factor alterations during progression of human prostate cancer. Mol. Oncol. 2016, 10, 879-894. [CrossRef] 
10. Chen, L.; Ambrosone, C.B.; Lee, J.; Sellers, T.A.; Pow-Sang, J.; Park, J.Y. Association between polymorphisms in the DNA repair genes XRCC1 and APE1, and the risk of prostate cancer in white and black Americans. J. Urol. 2006, 175, 108-112; discussion 112. [CrossRef]

11. Park, J.Y.; Huang, Y.; Sellers, T.A. Single nucleotide polymorphisms in DNA repair genes and prostate cancer risk. Methods Mol. Biol. 2009, 471, 361-385. [CrossRef]

12. Xu, N.; Wu, Y.P.; Ke, Z.B.; Liang, Y.C.; Cai, H.; Su, W.T.; Tao, X.; Chen, S.H.; Zheng, Q.S.; Wei, Y.; et al. Identification of key DNA methylation-driven genes in prostate adenocarcinoma: An integrative analysis of TCGA methylation data. J. Transl. Med. 2019, 17, 311. [CrossRef]

13. Pecorino, L. Molecular Biology of Cancer-Mechanisms, Targets and Therapeutics, 4th ed.; Oxford University Press: Oxford UK, 2016.

14. Carleton, N.M.; Zhu, G.; Gorbounov, M.; Miller, M.C.; Pienta, K.J.; Resar, L.M.S.; Veltri, R.W. PBOV1 as a potential biomarker for more advanced prostate cancer based on protein and digital histomorphometric analysis. Prostate 2018, 78, 547-559. [CrossRef]

15. Komura, K.; Sweeney, C.J.; Inamoto, T.; Ibuki, N.; Azuma, H.; Kantoff, P.W. Current treatment strategies for advanced prostate cancer. Int. J. Urol. 2018, 25, 220-231. [CrossRef] [PubMed]

16. Giudice, A.; Montella, M.; Boccellino, M.; Crispo, A.; D’Arena, G.; Bimonte, S.; Facchini, G.; Ciliberto, G.; Botti, G.; Quagliuolo, L.; et al. Epigenetic Changes Induced by Green Tea Catechins are Associated with Prostate Cancer. Curr. Mol. Med. 2017, 17, 405-420. [CrossRef] [PubMed]

17. Park, J.Y. Promoter hypermethylation in prostate cancer. Cancer Control 2010, 17, 245-255. [CrossRef] [PubMed]

18. Yang, M.; Park, J.Y. DNA methylation in promoter region as biomarkers in prostate cancer. Methods Mol. Biol. 2012, 863, 67-109. [CrossRef] [PubMed]

19. Devaney, J.M.; Wang, S.; Funda, S.; Long, J.; Taghipour, D.J.; Tbaishat, R.; Furbert-Harris, P.; Ittmann, M.; Kwabi-Addo, B. Identification of novel DNA-methylated genes that correlate with human prostate cancer and high-grade prostatic intraepithelial neoplasia. Prostate Cancer Prostatic Dis. 2013, 16, 292-300. [CrossRef]

20. Kim, J.W.; Kim, S.T.; Turner, A.R.; Young, T.; Smith, S.; Liu, W.; Lindberg, J.; Egevad, L.; Gronberg, H.; Isaacs, W.B.; et al. Identification of new differentially methylated genes that have potential functional consequences in prostate cancer. PLoS ONE 2012, 7, e48455. [CrossRef]

21. Geybels, M.S.; Zhao, S.; Wong, C.J.; Bibikova, M.; Klotzle, B.; Wu, M.; Ostrander, E.A.; Fan, J.B.; Feng, Z.; Stanford, J.L. Epigenomic profiling of DNA methylation in paired prostate cancer versus adjacent benign tissue. Prostate 2015, 75, 1941-1950. [CrossRef]

22. Apprey, V.; Wang, S.; Tang, W.; Kittles, R.A.; Southerland, W.M.; Ittmann, M.; Kwabi-Addo, B. Association of Genetic Ancestry With DNA Methylation Changes in Prostate Cancer Disparity. Anticancer Res. 2019, 39, 5861-5866. [CrossRef]

23. Strand, S.H.; Orntoft, T.F.; Sorensen, K.D. Prognostic DNA methylation markers for prostate cancer. Int. J. Mol. Sci. 2014, 15, 16544-16576. [CrossRef]

24. Ruf, C.G.; Linbecker, M.; Port, M.; Riecke, A.; Schmelz, H.U.; Wagner, W.; Meineke, V.; Abend, M. Predicting metastasized seminoma using gene expression. BJU Int. 2012, 110, E14-E20. [CrossRef]

25. An, L.; Dong, C.; Li, J.; Chen, J.; Yuan, J.; Huang, J.; Chan, K.M.; Yu, C.-h.; Huen, M.S.Y. RNF169 limits 53BP1 deposition at DSBs to stimulate single-strand annealing repair. Proc. Natl. Acad. Sci. USA 2018, 115, E8286. [CrossRef] [PubMed]

26. Li, D.; Hao, X.; Song, Y. Identification of the Key MicroRNAs and the miRNA-mRNA Regulatory Pathways in Prostate Cancer by Bioinformatics Methods. Biomed. Res. Int. 2018, 2018, 6204128. [CrossRef] [PubMed]

27. Mukhopadhyay, N.K.; Ferdinand, A.S.; Mukhopadhyay, L.; Cinar, B.; Lutchman, M.; Richie, J.P.; Freeman, M.R.; Liu, B.C. Unraveling androgen receptor interactomes by an array-based method: Discovery of proto-oncoprotein c-Rel as a negative regulator of androgen receptor. Exp. Cell Res. 2006, 312, 3782-3795. [CrossRef] [PubMed]

28. Mukhopadhyay, N.K.; Cinar, B.; Mukhopadhyay, L.; Lutchman, M.; Ferdinand, A.S.; Kim, J.; Chung, L.W.; Adam, R.M.; Ray, S.K.; Leiter, A.B.; et al. The zinc finger protein ras-responsive element binding protein-1 is a coregulator of the androgen receptor: Implications for the role of the Ras pathway in enhancing androgenic signaling in prostate cancer. Mol. Endocrinol. 2007, 21, 2056-2070. [CrossRef]

29. Mukund, K.; Syulyukina, N.; Ramamoorthy, S.; Subramaniam, S. Right and left-sided colon cancers-Specificity of molecular mechanisms in tumorigenesis and progression. BMC Cancer 2020, 20, 317. [CrossRef]

30. Eun, H.S.; Cho, S.Y.; Lee, B.S.; Seong, I.O.; Kim, K.H. Profiling cytochrome P450 family 4 gene expression in human hepatocellular carcinoma. Mol. Med. Rep. 2018, 18, 4865-4876. [CrossRef]

31. Zhu, S.L.; Wang, L.; Cao, Z.Y.; Wang, J.; Jing, M.Z.; Xia, Z.C.; Ao, F.; Ye, L.B.; Liu, S.; Zhu, Y. Inducible CYP4F12 enhances Hepatitis $C$ virus infection via association with viral nonstructural protein 5B. Biochem. Biophys. Res. Commun. 2016, 471, 95-102. [CrossRef]

32. Huang, W.; Zhao, C.; Zhong, H.; Zhang, S.; Xia, Y.; Cai, Z. Bisphenol S induced epigenetic and transcriptional changes in human breast cancer cell line MCF-7. Environ. Pollut. 2019, 246, 697-703. [CrossRef]

33. Abdullah, M.; Choo, C.W.; Alias, H.; Abdul Rahman, E.J.; Mohd Ibrahim, H.; Jamal, R.; Hussin, N.H. ADAMTSL5 and CDH11: Putative epigenetic markers for therapeutic resistance in acute lymphoblastic leukemia. Hematology 2017, 22, 386-391. [CrossRef]

34. Li, T.Q.; Feng, C.Q.; Zou, Y.G.; Shi, R.; Liang, S.; Mao, X.M. Literature-mining and bioinformatic analysis of androgen-independent prostate cancer-specific genes. Zhonghua Nan Ke Xue 2009, 15, 1102-1107.

35. Fang, L.; Hou, J.; Cao, Y.; Shan, J.J.; Zhao, J. Spinster homolog 2 in cancers, its functions and mechanisms. Cell. Signal. 2020, 109821. [CrossRef] 
36. Brizuela, L.; Martin, C.; Jeannot, P.; Ader, I.; Gstalder, C.; Andrieu, G.; Bocquet, M.; Laffosse, J.M.; Gomez-Brouchet, A.; Malavaud, B.; et al. Osteoblast-derived sphingosine 1-phosphate to induce proliferation and confer resistance to therapeutics to bone metastasis-derived prostate cancer cells. Mol. Oncol. 2014, 8, 1181-1195. [CrossRef] [PubMed]

37. Bradley, E.; Dasgupta, S.; Jiang, X.; Zhao, X.; Zhu, G.; He, Q.; Dinkins, M.; Bieberich, E.; Wang, G. Critical role of Spns2, a sphingosine-1-phosphate transporter, in lung cancer cell survival and migration. PLoS ONE 2014, 9, e110119. [CrossRef] [PubMed]

38. Huang, W.; Qian, T.; Cheng, Z.; Zeng, T.; Si, C.; Liu, C.; Deng, C.; Ye, X.; Liu, Y.; Cui, L.; et al. Prognostic significance of Spinster homolog gene family in acute myeloid leukemia. J. Cancer 2020, 11, 4581-4588. [CrossRef] [PubMed]

39. Sawaki, K.; Kanda, M.; Miwa, T.; Umeda, S.; Tanaka, H.; Tanaka, C.; Kobayashi, D.; Suenaga, M.; Hattori, N.; Hayashi, M.; et al. Troponin I2 as a Specific Biomarker for Prediction of Peritoneal Metastasis in Gastric Cancer. Ann. Surg. Oncol. 2018, 25, 2083-2090. [CrossRef] [PubMed]

40. Zengin, T.; Onal-Suzek, T. Analysis of genomic and transcriptomic variations as prognostic signature for lung adenocarcinoma. BMC Bioinform. 2020, 21, 368. [CrossRef] [PubMed]

41. Wang, X.; Cheng, Y.; Yan, L.L.; An, R.; Wang, X.Y.; Wang, H.Y. Exploring DNA Methylation Profiles Altered in Cryptogenic Hepatocellular Carcinomas by High-Throughput Targeted DNA Methylation Sequencing: A Preliminary Study for Cryptogenic Hepatocellular Carcinoma. OncoTargets Ther. 2020, 13, 9901-9916. [CrossRef]

42. Xing, X.; Mu, N.; Yuan, X.; Wang, N.; Juhlin, C.C.; Straat, K.; Larsson, C.; Xu, D. PLEKHS1 Over-Expression is Associated with Metastases and Poor Outcomes in Papillary Thyroid Carcinoma. Cancers 2020, 12, 2133. [CrossRef]

43. Yan, J.; Zhou, X.; Pan, D. A case of one lung adenocarcinoma patient harboring a novel FAM179A-ALK (F1, A19) rearrangement responding to lorlatinib treatment. Lung Cancer 2020, 147, 26-29. [CrossRef]

44. Lee, D.; Ha, M.; Hong, C.M.; Kim, J.; Park, S.M.; Park, D.; Sohn, D.H.; Shin, H.J.; Yu, H.S.; Kim, C.D.; et al. GABRQ expression is a potential prognostic marker for patients with clear cell renal cell carcinoma. Oncol. Lett. 2019, 18, 5731-5738. [CrossRef]

45. Li, Y.H.; Liu, Y.; Li, Y.D.; Liu, Y.H.; Li, F.; Ju, Q.; Xie, P.L.; Li, G.C. GABA stimulates human hepatocellular carcinoma growth through overexpressed GABAA receptor theta subunit. World J. Gastroenterol. WJG 2012, 18, 2704-2711. [CrossRef] [PubMed]

46. Wheeler, M.A.; Ayyagari, R.R.; Wheeler, G.L.; Weiss, R.M. Regulation of cyclic nucleotides in the urinary tract. J. Smooth Muscle Res. 2005, 41, 1-21. [CrossRef]

47. Arakawa, K.; Maehara, S.; Yuge, N.; Ishikawa, M.; Miyazaki, Y.; Naba, H.; Kato, Y.; Nakao, K. Pharmacological characterization of a novel potent, selective, and orally active phosphodiesterase 10A inhibitor, PDM-042 [(E)-4-(2-(2-(5,8-dimethyl[1,2,4]triazolo[1,5-a]pyrazin-2-yl)vinyl)-6-(pyrrolidi n-1-yl)pyrimidin-4-yl)morpholine] in rats: Potential for the treatment of schizophrenia. Pharmacol. Res. Perspect. 2016, 4, e00241. [CrossRef] [PubMed]

48. Li, N.; Lee, K.; Xi, Y.; Zhu, B.; Gary, B.D.; Ramirez-Alcantara, V.; Gurpinar, E.; Canzoneri, J.C.; Fajardo, A.; Sigler, S.; et al. Phosphodiesterase 10A: A novel target for selective inhibition of colon tumor cell growth and beta-catenin-dependent TCF transcriptional activity. Oncogene 2015, 34, 1499-1509. [CrossRef]

49. Hennenberg, M.; Schott, M.; Kan, A.; Keller, P.; Tamalunas, A.; Ciotkowska, A.; Rutz, B.; Wang, Y.; Strittmatter, F.; Herlemann, A.; et al. Inhibition of Adrenergic and Non-Adrenergic Smooth Muscle Contraction in the Human Prostate by the Phosphodiesterase 10-Selective Inhibitor TC-E 5005. Prostate 2016, 76, 1364-1374. [CrossRef]

50. Guard, S.E.; Poss, Z.C.; Ebmeier, C.C.; Pagratis, M.; Simpson, H.; Taatjes, D.J.; Old, W.M. The nuclear interactome of DYRK1A reveals a functional role in DNA damage repair. Sci. Rep. 2019, 9, 6539. [CrossRef] [PubMed]

51. Menon, V.R.; Ananthapadmanabhan, V.; Swanson, S.; Saini, S.; Sesay, F.; Yakovlev, V.; Florens, L.; DeCaprio, J.A.; Washburn, M.P.; Dozmorov, M.; et al. DYRK1A regulates the recruitment of 53BP1 to the sites of DNA damage in part through interaction with RNF169. Cell Cycle 2019, 18, 531-551. [CrossRef]

52. Roewenstrunk, J.; Di Vona, C.; Chen, J.; Borras, E.; Dong, C.; Arato, K.; Sabido, E.; Huen, M.S.Y.; de la Luna, S. A comprehensive proteomics-based interaction screen that links DYRK1A to RNF169 and to the DNA damage response. Sci. Rep. 2019, 9, 6014. [CrossRef]

53. Laham, A.J.; Saber-Ayad, M.; El-Awady, R. DYRK1A: A down syndrome-related dual protein kinase with a versatile role in tumorigenesis. Cell. Mol. Life Sci. 2020, 1-7. [CrossRef]

54. Frank, S.; Nelson, P.; Vasioukhin, V. Recent advances in prostate cancer research: Large-scale genomic analyses reveal novel driver mutations and DNA repair defects. F1000Research 2018, 2. [CrossRef]

55. Dhawan, M.; Ryan, C.J.; Ashworth, A. DNA Repair Deficiency Is Common in Advanced Prostate Cancer: New Therapeutic Opportunities. Oncologist 2016, 21, 940-945. [CrossRef] [PubMed]

56. Aryee, M.J.; Jaffe, A.E.; Corrada-Bravo, H.; Ladd-Acosta, C.; Feinberg, A.P.; Hansen, K.D.; Irizarry, R.A. Minfi: A flexible and comprehensive Bioconductor package for the analysis of Infinium DNA methylation microarrays. Bioinformatics 2014, 30, 1363-1369. [CrossRef] [PubMed]

57. Fortin, J.-P.; Triche, T.J., Jr.; Hansen, K.D. Preprocessing, normalization and integration of the Illumina HumanMethylationEPIC array with minfi. Bioinformatics 2016, 33, 558-560. [CrossRef] [PubMed]

58. Triche, T.J., Jr.; Weisenberger, D.J.; Van Den Berg, D.; Laird, P.W.; Siegmund, K.D. Low-level processing of Illumina Infinium DNA Methylation BeadArrays. Nucleic Acids Res. 2013, 41, e90. [CrossRef] [PubMed]

59. Fortin, J.-P.; Labbe, A.; Lemire, M.; Zanke, B.W.; Hudson, T.J.; Fertig, E.J.; Greenwood, C.M.T.; Hansen, K.D. Functional normalization of 450k methylation array data improves replication in large cancer studies. Genome Biol. 2014, 15, 503. [CrossRef] [PubMed] 
60. Du, P.; Zhang, X.; Huang, C.-C.; Jafari, N.; Kibbe, W.A.; Hou, L.; Lin, S.M. Comparison of Beta-value and M-value methods for quantifying methylation levels by microarray analysis. BMC Bioinform. 2010, 11, 587. [CrossRef]

61. Johnson, W.E.; Li, C.; Rabinovic, A. Adjusting batch effects in microarray expression data using empirical Bayes methods. Biostatistics 2007, 8, 118-127. [CrossRef]

62. Wilhelm-Benartzi, C.S.; Koestler, D.C.; Karagas, M.R.; Flanagan, J.M.; Christensen, B.C.; Kelsey, K.T.; Marsit, C.J.; Houseman, E.A.; Brown, R. Review of processing and analysis methods for DNA methylation array data. Br. J. Cancer 2013, 109, 1394-1402. [CrossRef]

63. Jaffe, A.E.; Murakami, P.; Lee, H.; Leek, J.T.; Fallin, M.D.; Feinberg, A.P.; Irizarry, R.A. Bump hunting to identify differentially methylated regions in epigenetic epidemiology studies. Int. J. Epidemiol. 2012, 41, 200-209. [CrossRef]

64. Siegel, E.M.; Berglund, A.E.; Riggs, B.M.; Eschrich, S.A.; Putney, R.M.; Ajidahun, A.O.; Coppola, D.; Shibata, D. Expanding Epigenomics to Archived FFPE Tissues: An Evaluation of DNA Repair Methodologies. Cancer Epidemiol. Biomark. Prev. 2014, 23, 2622-2631. [CrossRef]

65. Siegel, E.M.; Eschrich, S.; Winter, K.; Riggs, B.; Berglund, A.; Ajidahun, A.; Simko, J.; Moughan, J.; Ajani, J.; Magliocco, A. Epigenomic Characterization of Locally Advanced Anal Cancer: A Radiation Therapy Oncology Group 98-11 Specimen Study. Dis. Colon Rectum 2014, 57, 941-957. [CrossRef]

66. Konno, H.; Yamauchi, S.; Berglund, A.; Putney, R.M.; Mulé, J.J.; Barber, G.N. Suppression of STING signaling through epigenetic silencing and missense mutation impedes DNA damage mediated cytokine production. Oncogene 2018, 37, 2037-2051. [CrossRef] [PubMed]

67. Yuan, J.; Hu, Z.; Mahal, B.A.; Zhao, S.D.; Kensler, K.H.; Pi, J.; Hu, X.; Zhang, Y.; Wang, Y.; Jiang, J.; et al. Integrated Analysis of Genetic Ancestry and Genomic Alterations across Cancers. Cancer Cell 2018, 34, 549-560.e9. [CrossRef] [PubMed] 